\title{
Dengue severity in the elderly in Puerto Rico
}

\author{
Enid J. García-Rivera ${ }^{1}$ and José G. Rigau-Pérez ${ }^{1}$
}

ABSTRACT Objective. Severe dengue affects all age groups in the Americas, but little detailed information is available about this disease in the elderly. The objective of this article is to describe the disease in this age group.

Methods. We reviewed suspected dengue-case investigation forms submitted with diagnostic samples as well as clinical reports from infection control nurses in Puerto Rico, for the period of 1994 through 1999.

Results. We assigned the laboratory-positive case-patients to four age groups: infants (1 year: 554), youth (2 to 18 years: 6 857), adults (19 to 64 years: 9 433), and elderly ( $\geq 65$ years: 822). Regardless of infecting serotype, the elderly were more likely to have been hospitalized $(48 \%$ vs. $33 \%)(\mathrm{P}<0.01)$ and were less likely to show hemorrhage $(26 \%$ vs. $33 \%)$ $(\mathrm{P}<0.01)$. On multivariate analysis, controlling for gender and the presence of hemorrhage, the elderly had a higher risk for hospitalization and death than did the youths and the adults. Conclusions. The elderly appear to be more likely than youth and younger adults to develop severe illness when infected with the dengue virus, in a pattern similar to that of infants. The clinical evaluation of elderly patients with dengue must include a careful assessment of increased capillary permeability and occult hemorrhage in order to avoid complications from delayed identification and treatment of severe dengue infection. These findings are of increasing importance for dengue epidemiology and medical care in view of the expanding nature of dengue and dengue hemorrhagic fever in a world that also has a growing number and proportion of elderly persons.

Key words Dengue, aged, Puerto Rico.

Dengue is an acute viral disease transmitted by Aedes mosquitoes, with a global distribution in tropical and subtropical areas. Most dengue infections are asymptomatic, and disease manifestations may range from minimal symptoms to death. The syn-

\footnotetext{
1 United States of America, Centers for Disease Control and Prevention, Division of Vector-Borne Infectious Diseases, Dengue Branch, San Juan, Puerto Rico. Send correspondence to: Enid J. García-Rivera, Dengue Branch, Division of VectorBorne Infectious Diseases, Centers for Disease Control and Prevention, Calle Cañada 1342, San Juan, Puerto Rico 00920-3860, United States of America; telephone: (787) 706-2399; fax: (787) 7062496; e-mail: ecg3@cdc.gov
}

drome known as dengue fever (DF) produces fever of acute onset, severe headache, myalgia or arthralgia, nausea or vomiting, and rash. On the other hand, dengue hemorrhagic fever (DHF) and dengue shock syndrome (DSS) are life-threatening illnesses associated with fever, hemorrhage, thrombocytopenia, and increased vascular permeability (1).

For the last three decades, dengue infection has been reemerging as an important cause of illness in the world, and most Central American and Caribbean countries have had notable epidemics of DHF (2). With this resurgence, the geographic distribution of the disease has increased, and it has been transmitted to a broader spectrum of the population. Severe dengue infection has been most frequently associated with younger age groups, on the basis of excellent studies conducted mostly in Southeast Asia (312). In contrast, in the Americas, severe dengue infection has been reported among all age groups (13-20). The elderly (aged $\geq 65$ years) have not been the subject of earlier studies of risk factors or clinical manifestations of dengue infection.

Aging is associated with atypical symptoms and higher rates of illness and death due to increased suscepti- 
bility to infections in general. This may be related to exogenous or endogenous factors such as environmental conditions, the presence of comorbid disease, and physiologic or immunologic changes (21). Whether the elderly differ from other age groups in clinical manifestations, disease severity, or risk factors associated with severe dengue is not known.

An excellent opportunity to evaluate such differences came from the laboratory-based surveillance system for dengue maintained by the Puerto Rico Department of Health in collaboration with the Dengue Branch, a unit of the Centers for Disease Control and Prevention (CDC) of the United States of America that is located in San Juan, Puerto Rico. A commonwealth associated with the United States, the island of Puerto Rico is located in the Caribbean and has an area of 3454 square miles $\left(9104 \mathrm{~km}^{2}\right)$. In year 2000 the population was 3808610 and $11 \%$ were aged 65 years or older (22). Puerto Rico is divided into $78 \mathrm{mu}-$ nicipios. Each municipio has an urban or semiurban nucleus (city or town) and may include both urban and rural areas.

In Puerto Rico, dengue is endemic and intermittently epidemic. The most recent islandwide outbreaks occurred in 1994 and 1998 (23). Each year, the dengue surveillance system receives reports for dengue patients in all age groups and from all municipios. The purpose of this study was to characterize, using laboratory-based surveillance information, the clinical manifestations of dengue infection and the risk factors associated with severe dengue infection in the elderly, in comparison to other age groups in Puerto Rico.

\section{METHODS}

\section{Surveillance data}

We analyzed surveillance data for case-patients in Puerto Rico with onset between 1 January 1994 and 15 October 1999. The CDC Dengue Branch receives blood specimens from clinics, hospitals, and laboratories throughout Puerto Rico. The samples are accompanied by a dengue case investigation form (DCIF), which includes demographic and clinical information, including whether the patient had developed hemorrhagic manifestations or was hospitalized at the time the blood specimen was drawn. Reports from hospital infection control nurses (ICNs), who voluntarily submit detailed clinical information from inpatients with suspected dengue, were also analyzed.

\section{Laboratory data}

Serum samples collected less than 6 days after the onset of symptoms (acute-phase samples) were processed for virus isolation in either $\mathrm{C} 6 / 36$ mosquito cell cultures or inoculated into Toxorhynchites amboinensis or Aedes aegypti mosquitoes (24). Dengue viruses were identified by the use of serotypespecific monoclonal antibodies in an indirect fluorescent antibody test on virus-infected cell cultures or tissue from inoculated mosquitoes. Serum specimens collected 6 days or more after the onset of illness (convalescentphase samples) were tested for antidengue immunoglobulin M (IgM) by the IgM antibody-capture enzymelinked immunosorbent assay (MACELISA) (25). If a serum specimen gave positive results for the virus, it was further evaluated with the immunoglobulin $G$ ( $I g G)$ ELISA to determine whether the infection was primary or secondary $(26,27)$.

\section{Case classification}

Patients with clinical manifestations compatible with dengue whose serum specimens were referred for laboratory diagnosis to the CDC Dengue Branch were considered to have a suspected case of dengue. Confirmation of current dengue infection was based on the following criteria: 1) dengue virus isolation from serum or autopsy tissue samples (virus-positive cases) or 2) seroconversion from negative to positive or a fourfold or greater change in anti-dengue antibody titers in paired serum samples. Probable dengue case-patients were those individuals in whom a single serum sample was positive for anti-dengue IgM or showed anti-dengue IgG antibody titer by ELISA $\geq 163840$. For this study, confirmed and probable case-patients were considered together as laboratorypositive case-patients. Single specimens negative for virus or for antidengue IgM antibody, if collected 5 or fewer days from the onset of symptoms, were considered nondiagnostic, and the case was categorized as indeterminate. In the 1994 and 1998 epidemics, priority for testing was given to samples from more severely ill patients, regardless of age, or from municipalities where an increase in incidence had not been previously detected. Samples that were not processed because of the criteria for testing applied during the 1994 and 1998 epidemics were considered nondiagnostic, and the case was also categorized as indeterminate. In specimens collected 6 or more days after the onset of symptoms, the absence of IgM was considered to rule out the diagnosis of dengue, and the case-patient was considered negative for dengue.

Suspected dengue case-patients were classified on the basis of age (by age group), laboratory diagnosis (by serologic or virologic testing), immune response (primary vs. secondary dengue infection), and severity (DF vs. DHF/DSS).

All patients were assigned to one of four age groups: infants (age $\leq 1$ year), youths (2 to 18 years), adults (19 to 64 years), or the elderly ( $\geq 65$ years). Age was defined as the age at onset of symptoms, stated on the DCIF or the ICN reports. Case-patients in whom age was unknown were excluded from the analysis. The comparisons between the age groups were limited to laboratory-positive case-patients.

Patients were classified as having current primary or secondary cases on the basis of the anti-dengue antibody types and titers in virus-positive acute-phase serum samples. A patient with a current primary case was de- 
fined as having the virus isolated from an acute-phase serum sample with no detectable anti-dengue IgG antibody by IgG ELISA. A patient with a current secondary case was defined as having the virus isolated from an acute-phase serum sample with an anti-dengue IgG antibody titer by IgG ELISA (27).

Only the ICN reports provided sufficient information to allow for clinical classification of cases. Laboratorypositive hospitalized case-patients were classified as having DF, DHF, or DSS by using the World Health Organization (WHO) case definitions (1).

\section{Statistical methods}

In this retrospective study, we used DCIF data to compare the proportion of patients who exhibited hemorrhage, who were hospitalized, or who died in each age group. Using ICN reports, we evaluated the presence of symptoms, the results of clinical testing, and the disease classification (DF vs. DHF/DSS) for each group among laboratory-positive hospitalized dengue case-patients. Only case-patients for which the information for a defined variable was present were included in the analysis. Statistical significance of comparisons was ascertained using chi-square, two-tailed Fisher's exact test, or single factor analysis of variance
(Kruskal-Wallis test). Post hoc analysis (multiple comparisons for percentages or means) was performed by using the Tukey test to compare each value with every other value, and the Dunnett procedure was used to compare the results from the elderly versus those from each of the other age groups (28).

Using stratified univariate analysis, we compared the association between each risk factor (gender, history of hemorrhage, immunologic status, and virus serotype) and each outcome (proportions of hospitalized and fatal cases) in each age group. For multivariate analysis, logistic regression models were used to identify independent factors associated with hospitalization and death. Models were tested for interaction and confounders. Epi Info version $6.04 \mathrm{~b}$ software (29) and Computer Programs for Epidemiologists (PEPI) version 3.01 software (30) were used for all statistical analyses.

\section{RESULTS}

From 1 January 1994 to 15 October 1999, specimens from 59669 patients with suspected dengue in Puerto Rico were referred for laboratory diagnosis to CDC's Dengue Branch. Among them, 2271 (3.8\%) were from infants, 24395 (40.9\%) were from youth, 29920 (50.1\%) were from adults, and 3083
(5.2\%) were from elderly patients. From 1994 to 1999, the proportion of suspected dengue cases in Puerto Rico in persons aged 65 years or older increased from $4.4 \%$ to $7.3 \%$. A definitive laboratory diagnosis was made in 22743 of the suspected cases $(38.1 \%)$. There were 17666 (29.6\%) laboratorypositive cases (14 512 [82\%] by serologic and 3154 [18\%] by virologic methods), 5077 (8.5\%) specimens were classified as negative, and 36926 $(61.9 \%)$ were indeterminate. By age group, the proportions of laboratorypositive results were: $24.4 \%$ (554 cases) in infants, $28.1 \%$ (6 857 cases) in youths, $31.5 \%$ (9 433 cases) in adults, and 26.6\% (822 cases) in the elderly. By dengue serotype, of the 3154 viral isolations, 761 of them (24.1\%) were DEN-1, 1294 (41.0\%) were DEN-2, 163 (5.2\%) were DEN-3, and 936 (29.7\%) were DEN-4.

As shown in Table 1, males made up a slight majority of the laboratorypositive dengue case-patients in every age group except the adults. Of the 44 patients with a laboratory-positive case who died during the study period, $22(50 \%)$ were male. DEN-4 was the predominant serotype among the elderly. The elderly showed the lowest incidence rate in a comparison with data for other age groups in the two nonepidemic years of 1996 and 1997. Among the 3154 virus-positive casepatients, 2379 of them $(75.4 \%)$ had a

TABLE 1. General characteristics of laboratory-positive dengue cases, by age group, Puerto Rico, 1994-1999

\begin{tabular}{|c|c|c|c|c|}
\hline & Infants & Youth & Adults & Elderly \\
\hline Gender ratio (male/female) & 1.13:1 & $1.05: 1$ & $0.89: 1$ & $1.10: 1$ \\
\hline Predominant serotype and (\%) & DEN-2 (34) & DEN-2 (39) & DEN-2 (44) & DEN-4 (46) \\
\hline \multicolumn{5}{|c|}{ Average incidence/ 1000 in two nonepidemic years } \\
\hline (1996 and 1997) & 0.51 & 0.71 & 0.51 & 0.24 \\
\hline Ratio of secondary to primary cases & $0.45: 1$ & $2: 1$ & $5: 1$ & $12: 1$ \\
\hline Proportion (\%) with any hemorrhage ${ }^{a}$ & $236 / 526(44.9)^{b}$ & $2068 / 6794(30.4)^{b}$ & $3242 / 9345(34.7)^{b}$ & $212 / 812(26.1)$ \\
\hline Proportion (\%) of hospitalized cases ${ }^{a}$ & $286 / 553(51.7)$ & $1896 / 6814(27.8)^{b}$ & $3256 / 9397(34.6)^{b}$ & $390 / 816(47.8)$ \\
\hline Proportion (\%) of fatal cases ${ }^{a}$ & $3 / 554(0.5)$ & $9 / 6857(0.1)^{b}$ & $25 / 9433(0.3)$ & $7 / 822(0.9)$ \\
\hline
\end{tabular}

\footnotetext{
a Number with characteristic/number in age group with evaluable responses.
}

b $P<0.05$ compared to elderly group. 
TABLE 2. Clinical characteristics for laboratory-positive hospitalized dengue cases, by age group, Puerto Rico, 1994-1999a

\begin{tabular}{|c|c|c|c|c|c|c|c|c|}
\hline \multirow[b]{2}{*}{ Characteristic } & \multicolumn{2}{|c|}{ Infants } & \multicolumn{2}{|c|}{ Youths } & \multicolumn{2}{|c|}{ Adults } & \multicolumn{2}{|c|}{ Elderly } \\
\hline & No. & $\%$ & No. & $\%$ & No. & $\%$ & No. & $\%$ \\
\hline \multicolumn{9}{|l|}{ Constitutional symptoms } \\
\hline Rash & 15 & $71.5^{b}$ & 245 & $49.4^{b}$ & 346 & $40.0^{b}$ & 27 & 25.7 \\
\hline Pleural or abdominal effusions & 2 & 10.5 & 13 & 3.0 & 9 & 1.2 & 2 & 2.2 \\
\hline Hepatomegaly & 2 & $10.5^{b}$ & 22 & $4.9^{b}$ & 30 & $3.8^{b}$ & 0 & 0.0 \\
\hline \multicolumn{9}{|l|}{ Hemorrhagic manifestations } \\
\hline Gum bleeding & 1 & 5.0 & 24 & 5.2 & 73 & $8.8^{b}$ & 3 & 2.9 \\
\hline Vaginal bleeding (women) & 0 & 0.0 & 10 & 2.2 & 33 & $4.2^{b}$ & 0 & 0.0 \\
\hline Hematuria & 0 & 0.0 & 13 & 2.8 & 32 & 4.0 & 3 & 2.9 \\
\hline Lower gastrointestinal bleeding & 1 & 5.9 & 12 & 2.9 & 19 & 2.6 & 8 & 8.1 \\
\hline Hematemesis & 2 & 10.0 & 27 & 5.8 & 43 & 5.2 & 3 & 2.9 \\
\hline Hemoptysis & 0 & 0.0 & 9 & 1.8 & 26 & 3.2 & 1 & 1.0 \\
\hline \multicolumn{9}{|l|}{ Severe outcome } \\
\hline Shock & 1 & 5.3 & 6 & 1.3 & 10 & 1.3 & 0 & 0.0 \\
\hline Death & 1 & 8.3 & 6 & 1.9 & 10 & 1.8 & 3 & 4.3 \\
\hline \multicolumn{9}{|l|}{ Disease classification } \\
\hline Dengue fever & 17 & 81.0 & 523 & 90.6 & 910 & 88.1 & 109 & 86.2 \\
\hline Dengue hemorrhagic fever & 3 & 14.3 & 51 & 8.8 & 119 & 11.5 & 17 & 13.5 \\
\hline Dengue shock syndrome & 1 & 4.8 & 3 & 0.5 & 4 & 0.4 & 0 & 0.0 \\
\hline
\end{tabular}

${ }^{\text {a }}$ Calculations for the distribution of clinical characteristics exclude missing values in the denominator.

${ }^{b} P<0.05$ when compared to elderly.

secondary type immune response. As expected, the ratio of secondary to primary infection increased with age, from $0.45: 1$ in infants to $12: 1$ in the elderly. The elderly also had a statistically significant lower frequency of hemorrhage and a statistically significant higher proportion of hospitalized patients than did either the youth or adult case-patients (Table 1). Regardless of infecting serotype, the elderly were more likely to have been hospitalized $(48 \%$ vs. $33 \%)(P<0.01)$ and were less likely to show hemorrhage $(26 \%$ vs. $33 \%)(P<0.01)$. The elderly had the highest case fatality rate $(0.9 \%)$, and the youth had the lowest $(0.1 \%)$; the difference was statistically significant $(P<0.05)$.

\section{Hospitalized laboratory-positive case-patients}

Among the 1757 laboratory-positive hospitalized case-patients from whom age information was available, no statistically significant differences were found among the age groups in terms of gender distribution (not shown), disease classification, or case fatality ratio (Table 2). Overall, 1559 (88.7\%) were classified as having dengue fever and $198(11.3 \%)$ as having DHF or DSS. No cases of DSS were reported among the elderly.

Also as shown in Table 2, rash, hepatomegaly, and mucocutaneous hemorrhage were observed less frequently in the elderly, but the elderly also experienced bleeding in the lower gastrointestinal tract and microhematuria (defined as a finding of more than five red blood cells per high power field, or a positive chemical test for blood in urine) more often than did the other age groups. Microhematuria was the most common hemorrhagic manifestation in all age groups except infants, and it was reported in $68 \%$ of the elderly with any hemorrhage. Excessive capillary permeability, mea- sured as the presence of hemoconcentration (hematocrit increased by $20 \%$ or more, or decreased as much after intravenous fluid therapy), or other objective evidence of increased capillary permeability (such as hypoproteinemia, pleural effusions, or other effusions), was also detected significantly more frequently in the elderly than in youths and adults. Among hospitalized patients, no clinically significant differences between the groups were found in mean maximum and minimum hematocrit, minimum blood pressure, platelet count, albumin levels, or liver enzyme levels (data not shown).

\section{Risk analysis}

When considering only laboratorypositive case-patients, male gender increased the risk for hospitalization for infants (odds ratio $(\mathrm{OR})=1.62,95 \%$ confidence interval $(\mathrm{CI})=1.14-2.30$ ) 
and youths $(\mathrm{OR}=1.13 ; 95 \% \mathrm{CI}=1.01-$ 1.26), and hemorrhage increased the risk of hospitalization in all groups except the elderly. Neither male gender nor history of hemorrhage significantly increased the risk of death for patients in any of the age groups.

When we looked at age subgroups among the elderly (65-69, 70-79, $80-89$, and 90 years or older), the frequency of reported hemorrhage, hospitalization, or disease outcome was similar. An increased risk for hemorrhage in comparison to other age groups was seen only in males 80-89 years old $(\mathrm{OR}=4.31 ; 95 \% \mathrm{CI}=1.46-$ 13.13). However, neither gender, hemorrhage, nor secondary infection increased the risk for hospitalization in any of the elderly age subgroups (data not shown).

Multiple regression analysis among the laboratory-positive patients showed that hemorrhage and male sex were independent risk factors for hospitalization (Table 3). Hemorrhage was also an independent risk factor for death. After adjustment for gender and the presence of hemorrhage, the elderly and infants had similar risks of hospitalization and death. The elderly had 2.4 times the risk of hospitalization as did youths, and 1.7 times the risk of adults. Also, the risk of death in the elderly was 6.8 times that of youths and 3.4 times that of adults.

\section{DISCUSSION}

Although dengue infection in adults has been described in prior publications (11, 14-20, 31-36), this study provides the first detailed analysis of clinical manifestations of dengue in the elderly (aged 65 years or older). Three markers of disease severity were evaluated in this study: the presence of hemorrhage, hospitalization, and fatal outcome. Even when the clinical presentations of dengue fever and severe dengue infection in this age group are similar to the disease presentations described in clinical studies in other age groups, subtle differences were found. Hemorrhages were reported less frequently in the elderly, who were also

TABLE 3. Multivariate analysis showing odds ratio (OR) and $95 \%$ confidence interval (Cl) for risk for hospitalization and death among laboratory-positive dengue cases in Puerto Rico, 1994-1999

\begin{tabular}{llllll}
\hline \multirow{2}{*}{ Groups compared } & \multicolumn{2}{c}{ Hospitalization } & & \multicolumn{2}{c}{ Death } \\
\cline { 5 - 6 } \cline { 5 - 6 } & OR & $95 \% \mathrm{Cl}$ & & OR & $95 \% \mathrm{Cl}$ \\
\hline Elderly vs. infants & 0.91 & $0.73-1.13$ & & 1.80 & $0.46-7.04$ \\
Elderly vs. youth & $2.43^{\mathrm{b}}$ & $2.10-2.82$ & & $6.78^{\mathrm{b}}$ & $2.51-18.3$ \\
Elderly vs. adults & $1.71^{\mathrm{b}}$ & $1.48-1.98$ & & $3.45^{\mathrm{b}}$ & $1.49-8.05$ \\
Hemorrhage vs. no-hemorrhage & $1.51^{\mathrm{b}}$ & $1.42-1.62$ & & $2.06^{\mathrm{b}}$ & $1.14-3.74$ \\
Males vs. females & $1.09^{\mathrm{b}}$ & $1.03-1.17$ & & 1.07 & $0.59-1.94$ \\
\hline
\end{tabular}

a The reference group is the second one in each of the pairings.

b $P<0.05$.

hospitalized more often and had a higher case fatality ratio than did youths and adults. These findings are of increasing importance for dengue epidemiology and medical care, in view of the expanding nature of dengue and DHF in a world that is facing an aging population.

Many of the clinical manifestations of dengue fever found in our study of the elderly are consistent with previous clinical descriptions in adults. Rash was less commonly found in the elderly (probably because of the relative frequency of secondary infections in this segment of the population (33)), and the percentage of DHF patients with hepatomegaly decreased with age (none of the elderly patients was observed to have hepatomegaly). Hepatic weight declines with age, and in vivo ultrasound studies have shown that liver volume is $17 \%$ to $28 \%$ lower in those over age 65 than in those under age 40 , which could be a contributing factor for this finding $(37,38)$.

Another finding to be kept in mind in the clinical evaluation of an elderly patient is that fewer hemorrhagic manifestations, especially mucosal and cutaneous hemorrhages, were reported in this age group. However, hemorrhage is a marker for severe disease and even though the aged report fewer hemorrhagic manifestations (overall), microhematuria and occult gastrointestinal bleeding occurred more frequently than did other hemorrhagic manifestations. Therefore, if obvious bleeding is not evident, it should be sought. As previously reported in DHF patients in Puerto Rico (14), in our study the most frequent hemorrhagic manifestation in all age groups except infants was microscopic hematuria. It was present in $40 \%$ of the elderly casepatients who exhibited hemorrhage when they sought treatment and was the only hemorrhagic manifestation in $68 \%$ of the 17 elderly case-patients with DHF. We also found a higher proportion of elderly patients with increased vascular permeability. The pathophysiological mechanism behind this is not clear, but the higher frequency of this important contributor to DHF (39-42) could be an important factor in the severity of dengue in the elderly.

Our study was based on surveillance data, which by its nature may have led to preferential reporting of severe cases and incomplete recording of important items such as hospitalization status and disease outcome. Differential reporting of symptoms by age, a potential explanation for our findings, could not be assessed with the data available, but less frequent reporting of hemorrhage based solely on the age of the patient would not be expected. If differential reporting were present, it would be related more to the source of reporting (e.g., physicians, nurses, or ICNs) and, therefore, should be equally distributed among all age groups.

We found that the elderly with dengue were hospitalized as often as infants and more frequently than youths and adults. This might be explained by the perception of both the 
infants and elderly as "fragile" since they are more likely to develop complications during any disease process and therefore require closer observation. This would lead to less-severe cases being hospitalized more often and also to an increase in the proportion of patients hospitalized due to a concern (age) unrelated to dengue. However, if age were the reason for differential rates of hospitalization, we would expect a lower case fatality rate among the elderly, because milder cases would inflate the denominator. Nevertheless, in our study we found the opposite, that is, a higher case fatality rate among the elderly. These considerations highlight the need for prospective clinical studies that include the elderly.

Dengue complications are enhanced in well-nourished children with good immune response (43). The nutritional and immune status of the elderly was not assessed in this study, but it is clear that even when the elderly may in general have diminished immunity, they still present with severe dengue. This requires further evaluation, in consideration of the multifactorial etiology of severe dengue infection. Another relevant contributor to the findings in this study might be concurrent disease, since aging is associated with the presence of chronic conditions and increased susceptibility to infectious disease. Previous studies have documented rare occurrences of severe dengue and co-infections or the presence of chronic diseases (44-46). Surveillance data such as those we analyzed do not provide information about coexisting diseases. However, a previous study of all 57 DHF patients documented in Puerto Rico in 1990 and 1991 (aged 0 to 86 years) found no evidence of comorbidity among them, suggesting that DHF diagnosis would rarely be attributed to comorbidity (14).

In summary, the elderly in Puerto Rico often develop severe illness when infected with the dengue virus. They show higher rates of hospitalization, DHF, and death than do infected youth and younger adults, in a pattern similar to that of infants. We applied the WHO case definition for DHF strictly, so DHF diagnosis was not applied differentially. An elderly case may present with increased vascular permeability and may require hospitalization (two markers of disease severity), even in the absence of evident hemorrhage. The clinical evaluation of elderly patients with suspected dengue must include a thorough clinical examination. An assessment of the occurrence of mild hemorrhage, including the presence of microhematuria, occult blood in stools, and increased capillary permeability is very important to avoid complications from delayed identification and treatment of severe dengue infection.

Acknowledgments. The authors gratefully acknowledge the assistance of hospital infection control nurses in Puerto Rico and of the laboratory staff, CDC, Dengue Branch, San Juan, Puerto Rico.

\section{REFERENCES}

1. World Health Organization. Dengue haemorrhagic fever. Diagnosis, treatment, prevention and control. 2nd ed. Geneva: WHO; 1997.

2. Pinheiro FP, Corber SJ. Global situation of dengue and dengue haemorrhagic fever, and its emergence in the Americas. World Health Stat Q 1997;50(3-4):161-169.

3. Thein S, Aung MM, Aye M, Zaw A, Aye K, Aye KM, et al. Risk factors in dengue shock syndrome. Am J Trop Med Hyg 1997;56:566572.

4. Burke DS, Nisalak A, Johnson DE, Scott RM. A prospective study of dengue infections in Bangkok. Am J Trop Med Hyg 1988;38:172180.

5. Sangkawibha N, Rojanasuphot S, Ahandrik S. Risk factors in dengue shock syndrome: a prospective study in Rayong, Thailand. Am J Epidemiol 1984;120:653-669.

6. George R, Lum LC. Clinical spectrum of dengue. In: Gubler DJ, Kuno G, eds. Dengue and dengue hemorrhagic syndrome. Wallingford, United Kingdom: CAB International; 1997. Pp. 89-113.

7. Nelson E. Hemorrhagic fever in children in Thailand. Trop Pediatr 1960;56:101-107.

8. Sumarmo, Wulur H, Jahja E, Gubler DJ, Suharyono W, Sorensen K. Clinical observations on virologically confirmed fatal dengue infections in Jakarta, Indonesia. Bull World Health Org 1983;61:693-701.

9. Halstead S, Nimmannitya S, Margiotta M. Dengue and chinkungunya virus infection in man in Thailand, 1962-1964. Am J Trop Med Hyg 1969;18:972-983.

10. Eram S, Setyabudi Y, Sadono I, Sutrisno S, Gubler DJ, Sulianti J. Epidemic dengue hemorrhagic fever in rural Indonesia. Am J Trop Med Hyg 1979;28:711-716.

11. Hayes C, Manaloto C, Gonzalez A, Ranoa P. Dengue infections in the Philippines: clinical and virological finding on 517 hospitalized patients. Am J Trop Med Hyg 1988;39:110-116.

12. Songco R, Hayes C, Leus CD, Manaloto COR. Dengue fever/dengue hemorrhagic fever in Filipino children: clinical experience during the 1983-1984 epidemic. Southeast Asian J Trop Med Publ Hlth 1987;18:284-290.

13. Gubler DJ. Dengue and dengue hemorrhagic fever: its history and resurgence as a global public health problem. In: Gubler DJ, Kuno G, eds. Dengue and dengue hemorrhagic fever. Wallingford, United Kingdom: CAB International; 1997. Pp. 1-22.

14. Rigau-Pérez JG, Puerto Rico Association of Epidemiologists. Clinical manifestations of dengue hemorrhagic fever in Puerto Rico 1990-1991. Rev Panam Salud Publica 1997;1(5):381-388.
15. Miagostovich MP, Ramos RG, Nicol AF, Nogueira RMR, Cuzzi-Maya T, Oliveira AV, et al. Retrospective study on dengue fatal cases. Clin Neuropath 1997;16(4):204-208.

16. Gomez Dantes H, Koopman JS, Addy CL, Zarate ML, Vaca Marin MA, Longini IM, et al. Dengue epidemics on the Pacific coast of Mexico. Int J Epid 1988;17(1):178-186.

17. Travassos da Rosa A, Vasconcelos $P$, Travassos da Rosa ES, Rodrigues SG, Mondet B, Cruz A, et al. Dengue epidemic in Belém, Pará, Brazil 1996-97. Emerg Inf Dis 2000;6(3): 298-301.

18. Rosso F, Restrepo de Meza MT, Alzate A, Muñóz J, Moreno $\mathrm{CH}$. Dengue hemorrágico en el Hospital Universitario del Valle, 19901992. Colombia Médica 1994;25(1):10-14.

19. Rodríguez Gómez JH, Calderón Moncloa JC. Dengue clásico: aspectos epidemiológicos en el Hospital de Apoyo Integrado Tarapoto-1990. Acta Médica Peruana 1992;16(3):187-193.

20. Díaz A, Kourí G, Guzmán MG, Lobaina L, Bravo J, Ruiz A, et al. Description of the clinical picture of dengue hemorrhagic fever/dengue shock syndrome (DHF/DSS) in adults. Bull Pan Am Health Organ 1988;22(2): 133-144.

21. Bell R, High K. Alterations of immune defense mechanisms in the elderly: the role of nutrition. Infect Med 1997;14:415-424. 
22. United States of America, Census Bureau. Census 2000 data for Puerto Rico. Available from: http:/ / www.census.gov/census2000/ states/pr.html [Internet site]. Accessed 15 January 2003.

23. Rigau-Perez JG, Ayala-Lopez A, GarcíaRivera EJ, Hudson SM, Vorndam V, Reiter P, et al. The reappearance of dengue- 3 and subsequent dengue- 4 and dengue- 1 epidemic in Puerto Rico in 1998. Am J Trop Med Hyg 2002;67:355-362.

24. Gubler DJ, Kuno G, Sather GE, Velez M, Oliver A. Mosquito cell cultures and specific monoclonal antibodies in surveillance for dengue viruses. Am J Trop Med Hyg 1984;33: 158-165.

25. Burke DS, Nisalak A, Ussery MA. Antibody capture immunoassay detection of Japanese encephalitis virus immunoglobulin $\mathrm{M}$ and $\mathrm{G}$ antibodies in cerebrospinal fluid. J Clin Microbiol 1982;15:1034-1042.

26. Chungue E, Marché G, Pichart R, Boutin JP, Roux J. Comparison of immunoglobulin $\mathrm{G}$ enzyme-linked immunosorbent assay (IgGELISA) and hemagglutination inhibition (HI) test for the detection of dengue antibodies: prevalence of dengue IgG-ELISA antibodies in Tahiti. Trans R Soc Trop Med Hyg 1989;83: 708-711.

27. Miagostovich MP, Nogueira RMR, dos Santos FB, Schartmayr HG, Araujo ESM, Vorndam V. Evaluation of an IgG enzyme-linked immunosorbent assay for dengue diagnosis. J Clin Virol 1999;14:183-189.

28. Zar JH. Biostatistical analysis. 2nd ed. Englewood Cliffs, New Jersey, United States of America: Prentice-Hall; 1984.

29. Dean AG, Dean JA, Coulombier D, Brendel KA, Smith DC, Burton AH, et al. Epi Info, ver- sion 6: a word processing, database, and statistics program for epidemiology on microcomputers. Atlanta, Georgia, United States: Centers for Disease Control and Prevention; 1994.

30. Abramson JH, Gahlinger PM. Computer programs for epidemiologists (PEPI). Version 3.01 Available from: http://www.usd-inc.com/ pepi.html [Internet site]. Accessed November 1999.

31. Wali JP, Biswas A, Handa R, Aggarwal P, Wig N, Dwivedi SN. Dengue hemorrhagic fever in adults: a prospective study of 110 cases. Trop Doct 1999;29:27-30.

32. Kuberski T, Rosen L, Reed D, Mataika J. Clinical and laboratory observations on patients with primary and secondary dengue type infectious with hemorrhagic manifestations in Fiji. Am J Trop Med Hyg 1977;26:775-783.

33. Cobra C, Rigau-Pérez J, Kuno G, Vorndam V. Symptoms of dengue fever in relation to host immunologic response and virus serotype, Puerto Rico, 1990-1991. Am J Epidemiol 1995; 142:1204-1211.

34. Guzman MG, Kouri GP, Bravo J, Soler M, Vazquez S, Morier L. Dengue hemorrhagic fever in Cuba, 1981: a retrospective seroepidemiologic study. Am J Trop Med Hyg 1990;42: 179-184.

35. Macridi NG. L'épidémie de dengue a Athènes. Rev Hyg Med Preventive 1929;51(4):241267.

36. Guzmán MG, Alvarez M, Rodríguez $R$ Rosario D, Vázquez S, Valdés L, et al. Fatal dengue hemorrhagic fever in Cuba, 1997. Int J Infect Dis 1999;3(3):130-135.

37. Merck \& Co. The aging liver. In: The Merck manual of geriatrics. 2nd ed. Merck \& Co. 1995. Available from: http://www.merck. com/pubs/mm_geriatrics/59x.htm [Internet site]. Accessed 28 June 2000.

38. Merck \& Co. Normal aging changes. In: The Merck manual of geriatrics. 2nd ed. Merck \& Co.; 1995. Available from: http://www. merck.com/pubs/mm_geriatrics/33x.htm [Internet site]. Accessed 28 June 2000.

39. Sen P, Middleton J, George P, Gombert M, Lee Douglas, Louria D. Host defense abnormalities and infections in older persons. Infect Urol 1995;8(1):23-29.

40. Kalayanarooj S, Vanghn DW, Nimmannitya S Early clinical and laboratory indicators of acute dengue illness. J Infect Dis 1997;176: 313-321.

41. Monath TP. Early indicators in acute dengue infection. Lancet 1997;350:1719-1720.

42. Kliks SC, Nisalak A, Brand W, Wahl L, Burke DS. Antibody-dependent enhancement of dengue virus growth in human monocytes as a risk factor for dengue hemorrhagic fever. Am J Trop Med Hyg 1989;40:444-451.

43. Thisyakorn U, Nimmannitya S. Nutritional status of children with dengue hemorrhagic fever. Clin Inf Dis 1993;16:295-297.

44. Bravo JR, Guzman MG, Kouri GP. Why dengue hemorrhagic fever in Cuba? Individual risk factors for dengue hemorrhagic fever/dengue shock syndrome (DHF/DSS).Trans R Soc Trop Med Hyg 1987;81:816-820.

45. Goh KT. Changing epidemiology of dengue in Singapore. Lancet 1995;346:1098.

46. Pancharoen C, Thisyakorn U. Coinfections in dengue patients. Pediatr Infect Dis J 1998;17: 81-82.

Manuscript received 9 April 2002. Revised version accepted for publication on 15 November 2002.

RESUMEN Objetivos. Las formas graves de dengue afectan a todos los grupos de edad en las Américas. Sin embargo, es escasa la información detallada sobre esta enfermedad en adultos mayores. El objetivo de este trabajo es describir esta enfermedad en personas de edad avanzada.

\section{Gravedad del dengue en adultos mayores de Puerto Rico}

Métodos. Se revisaron los formularios usados para investigar los casos sospechados de dengue que fueron enviados con muestras para el diagnóstico, así como los informes clínicos confeccionados por personal de enfermería dedicado al control de infecciones en Puerto Rico en el período entre 1994 y 1999.

Resultados. Los casos positivos según las pruebas de laboratorio fueron asignados a cuatro grupos de edad: niños ( $\leq 1$ año: 554 casos), jóvenes (de 2 a 18 años: 6857 casos) adultos (de 19 a 64 años: 9433 casos) y adultos mayores ( $\geq 65$ años: 822 casos). Independientemente del serotipo infectante, los adultos mayores fueron los más propensos a haber sido hospitalizados $(48 \%$ vs. $33 \%)(P<0,01)$ y los menos propensos a las hemorragias $(26 \%$ vs. $33 \%)(P<0,01)$. Según el análisis de múltiples variables, con datos controlados según el sexo y la presencia de hemorragia, los adultos mayores mostraron un mayor riesgo de ser hospitalizados y de morir que los jóvenes y los adultos.

Conclusiones. En comparación con los jóvenes y los adultos, los adultos mayores se muestran más propensos a desarrollar formas graves de dengue al ser infectados por el virus causal, siendo el patrón similar al de los niños. La evaluación clínica de los adultos mayores con dengue debe incluir una minuciosa evaluación del aumento de la permeabilidad capilar y de posibles hemorragias ocultas, con el fin de evitar complicaciones por la demora en identificar y tratar los casos graves de dengue. En vista de la propagación del dengue y de su forma hemorrágica, estos resultados son de una importancia creciente en lo referente a la epidemiología y la atención médica de los casos de dengue, en un mundo donde también van en aumento el número de adultos mayores y la proporción de la población que ellos representan. 